II Simpósio

Internacional

de Ourivesaria,

Joalheria e Design

\title{
A usabilidade do efêmero | Os desafios tecnológicos da joalheria contemporânea na adoção de materiais alternativos
}

The ephemeral usability / The contemporary jewelry technological challenges in the adoption of alternative materials.

\author{
GONÇALVES, Vivianne Ferreira; Mestranda; Universidade Federal de Pernambuco \\ vivianne.vfg@ufpe.br
}

BENATTI, Lia Paletta; Mestre; Universidade Federal de Juiz de Fora

lia.paletta@gmail.com

\author{
MARTINS, Laura Bezerra; Doutora; Universidade Federal de Pernambuco \\ laura.martins@ufpe.br
}
SILVA, Germannya D. A.; Doutora; Universidade Federal de Pernambuco germannya.asilva@ufpe.br

Palavras chave: joalheria contemporânea; agradabilidade; sementes; usabilidade.

\begin{abstract}
O presente artigo trata-se de uma revisão de literatura que discute as questões técnicas e de usabilidade da joia contemporânea para além da escolha de um material pelo seu caráter inovador ou indagador, aspecto comum na produção deste artefato. O trabalho faz parte da pesquisa de mestrado do PPgDesign da Universidade Federal de Pernambuco, em andamento, que visa estabelecer um viés ergonômico da aplicação de sementes, e a importância da adoção de técnicas e tecnologias no tratamento da superfície destes materiais visando a sua durabilidade. O método de pesquisa aplicado neste trabalho foi o da elaboração de um mapa mental a partir de Buzan (2009) a fim de relacionar os conceitos-chave da pesquisa estimulando a conexão de ideias e sentidos e, na sequência, um mapeamento dos trabalhos publicados nos últimos 15 anos. Como resultado, identificou-se que aspectos estéticos e simbólicos relacionados com a agradabilidade são mais recorrentes na produção de joias contemporâneas e que há uma lacuna de estudos que relacionem os aspectos técnicos e de usabilidade na produção de tais artefatos.
\end{abstract}

Keywords: contemporary jewelry; pleasantness; seeds; usability.

The present article is a literature rewiiew that discusses the technical and usability issues of contemporary jewelry beyond the choice of a material for its innovative or inquiring character, common aspect in the production of this artifact. The work is part of the master 's research of PPgDesign of the Federal University of Pernambuco, in progress, which aims to establish an ergonomic bias in the application of seeds, and the importance of adopting techniques and technologies in the surface treatment of these materials aiming at its durability. The research method applied in this work was the preparation of a mind map based on Buzan (2009) in order to relate the key concepts of the research, stimulating the connection of ideas and meanings and, subsequently, a mapping of the Works published in the last 15 years. As a result, it was identified that the aesthetic and symbolic aspects related to the pleasantness are more recurrent in contemporary jewelry and that there is a gap of studies that relate the technical and usability aspects in the production of such artifacts. 


\section{Introdução}

A expansão do mercado da joalheria contemporânea cresce na mesma proporção em que provoca inquietações e críticas em relação à preciosidade da joalheria tradicional. A seleção de materiais menos nobres e de baixo impacto ambiental fez surgir um novo mercado paralelo ao das joias tradicionais que faz uso de processos de exploração dos recursos naturais de alto impacto ambiental. Além disso, 'os insumos joalheiros como ouro, prata e gemas preciosas são recursos naturais finitos e que devem ser administrados para evitar seu esgotamento' (MILAN, 2019).

A cadeia do mercado de joias tradicionais tem a sua origem com a própria humanidade, que desde seus primórdios elabora adornos que evoluíram, em parte, ao que conhecemos hoje como a joalheria tradicional. Se, por um lado, a tradição expõe os altos valores de troca e de estima associados a este segmento, em contrapartida, os danos causados ao meio ambiente e aos povos originários de muitos países como o Brasil é preocupante '[...] pela devastação gerada pela mineração, através da remoção de grandes quantidades de terreno e pela geração de resíduos poluentes resultantes da purificação/beneficiamento destes materiais.'

(STRALIOTTO, 2008).

Uma pesquisa da Escola Nacional de Saúde Pública Sergio Arouca (Ensp/Fiocruz) identificou que $56 \%$ das mulheres e crianças da população Yanomami estavam com o limite de mercúrio acima do recomendado pela Organização Mundial de Saúde (OMS), devido a contaminação dos rios pelos garimpos de ouro na região, o que pode levar a diversos problemas de saúde como alterações no sistema nervoso central e em diversos outros órgãos do corpo. (LEONEL, 2019).

No segmento de adornos pessoais, incluindo a joalheria, há o uso de materiais alternativos àqueles determinados como "preciosos" que, em geral, apresentam valores de custo mais baixo, mas integram novas propostas estéticas e críticas ao setor, se enquadrando como joalheria contemporânea. Todavia, mesmo os materiais alternativos, apesar de serem muitas vezes oriundos de fontes naturais renováveis, o processo de captação e beneficiamento podem ser também prejudiciais ao meio ambiente e/ou ao entorno social. Para Manzini e Vezolli (2016) fazer design atualmente é pensar quais as relações que o produto terá com o meio ambiente ao longo do seu ciclo de vida, devendo esse produto ter baixo impacto ao longo desse processo de produção até o descarte. Considerar essas questões nas fases iniciais do projeto limitam os danos a serem reparados futuramente.

Norman (2002) ressalta que o bom design inclui todos os aspectos, desde o prazer estético e a criatividade aos princípios do bom uso e fácil operação, não havendo a necessidade de se sacrificar a usabilidade pela beleza e vice-versa. A joia que tem as suas características estéticas e simbólicas marcantes, como evidenciado ao longo de todos os séculos de produção, pode em seu processo projetual buscar incluir os aspectos de uso sem desconsiderar os demais aspectos.

A ISO 9241-11 relaciona a usabilidade a atributos que um produto venha a ter que facilite $o$ seu uso, de modo que o usuário trabalhe de maneira eficaz, com eficiência e satisfação. Já na agradabilidade expressada por Jordan (2000) se considera o indivíduo e as reações que o produto desperta nele, através das emoções e significados, não se atendo apenas às questões de forma e função. (DE MENEZES, 2007).

Diante dessas reflexões, este artigo traz um levantamento dos problemas de uso que cercam a temática da joia contemporânea com a adoção de materiais alternativos na sua composição (neste caso as sementes naturais) e, incita a discussão sobre a usabilidade e a agradabilidade percebidas em peças compostas por esses materiais.

A contribuição do trabalho fundamenta-se na delimitação e direcionamento da pesquisa de mestrado demonstrando a relevância do tema e enfatizando a lacuna do conhecimento a partir seguinte pergunta: Qual o estado da arte da relação entre a agradabilidade e usabilidade da joia contemporânea, especialmente as que utilizam sementes naturais em sua composição? 


\section{Referencial teórico}

\subsection{A joia contemporânea}

A diversificação de produtos anda a ritmo acelerado, no universo das joias. Um novo mercado que vem se desenvolvendo é o da joalheria contemporânea. São novos olhares sobre um produto que, por muito tempo, esteve ligado aos conceitos de eternidade e luxo. Para Mercaldi e Moura (2017) até meados do século XIX a definição da joia era mais fácil, visto que estava atrelada ao valor do material que era feito.

Com críticas ao consumo desenfreado de produtos industrializados e da exploração dos recursos naturais, a joia também passa a ser questionada quanto à necessidade de se utilizar apenas materiais oriundos da exploração mineral. Esse valor antes percebido em decorrência apenas da preciosidade dos metais e das gemas vem se modificando. Segundo Ashby e Johnson (2011, p:4): 'Precisamos evoluir de uma sociedade industrial impulsionada pelo consumismo para uma sociedade que respeita e aprecia os aspectos de eficiência e aparência'.

As questões envolvendo o uso de outros materiais nas joias têm levantado discussões sobre o significado que cada um atribui para o que seria considerado joia, e o cenário atual demonstra que o material dito nobre não é mais o único fator para essa denominação, por isso, o projeto da joia contemporânea citada por Mercaldi e Moura (2017, p:59):

[...] compreende objetos que são desenvolvidos e exploram a criação e seus elementos, tal como nas obras de arte e no sentido de explorar a criação e expressão, o que envolve o processo de criação, a escolha dos processos e materiais empregados, as temáticas abordadas pelo criador e a atitude do usuário/sujeito que opta em portar esse adorno e possuir a peça de joia.

A conceituação do que vem a ser a joia contemporânea está atrelada a vários fatores e por isso há uma dificuldade na sua definição. Já em movimentos passados como o Art and crafts houve o início do uso de outros materiais na joalheria e a se fazer uma crítica a preciosidade, apesar dos materiais serem um aspecto importante ela não se limita a isso, mas também se relaciona ao corpo e ao fazer do agora (MERCALDI; MOURA, 2017).

Nessas questões o usuário tem um importante papel que é o poder de ressignificar um artefato. Se ele aceita o novo e o convenciona socialmente, isso pode se estender a toda a comunidade (CARDOSO, 2013). Mais do que adornar, essa joia estará associada a diversos contextos e simbolismos presentes na sociedade atual, que dizem respeito tanto aos paradigmas relacionados aos materiais empregados, as apreensões e desejos do usuário e a forma que elas têm de identificar um grupo ou a cultura de determinada região através das suas composições.

\subsection{Uso de materiais alternativos}

Além dos materiais tradicionais, onde se concentram basicamente os metais nobres e as gemas, atualmente podem ser inseridos na produção da joalheira, materiais de diversas origens, dependendo do cenário em que se está inserido e das intenções pretendidas pelo designer. Os materiais podem tanto proporcionar funcionalidade técnica a um produto como Ihes conferir personalidade. (ASHBY; JOHNSON, 2011).

Guilgen e Kistmann (2012) fazem uma classificação dos materiais não tradicionais aplicados à joalheria como sendo: naturais, quando estão em sua estrutura original; naturais transformados, sendo aqueles que passam por processos de fabricação, polímeros naturais, a exemplo do chifre, polímeros sintéticos como os plásticos; e por fim os compostos, aqueles que agregam propriedades de dois ou mais materiais.

É possível dizer que, de maneira geral, eles se dividem em dois grandes grupos (figura 1), os de origem industrial, no qual são utilizados desde os mais duradouros como os polímeros aos mais efêmeros como o papel. Assim como podem se desenvolver em projetos dos mais simples e pontuais aos mais elaborados e conceituais. Já o segundo grupo seria os de origem natural minimamente processados, como madeira, escamas, fibras e sementes. 
Figura 1: Divisão dos materiais não convencionais aplicados na joalheria.

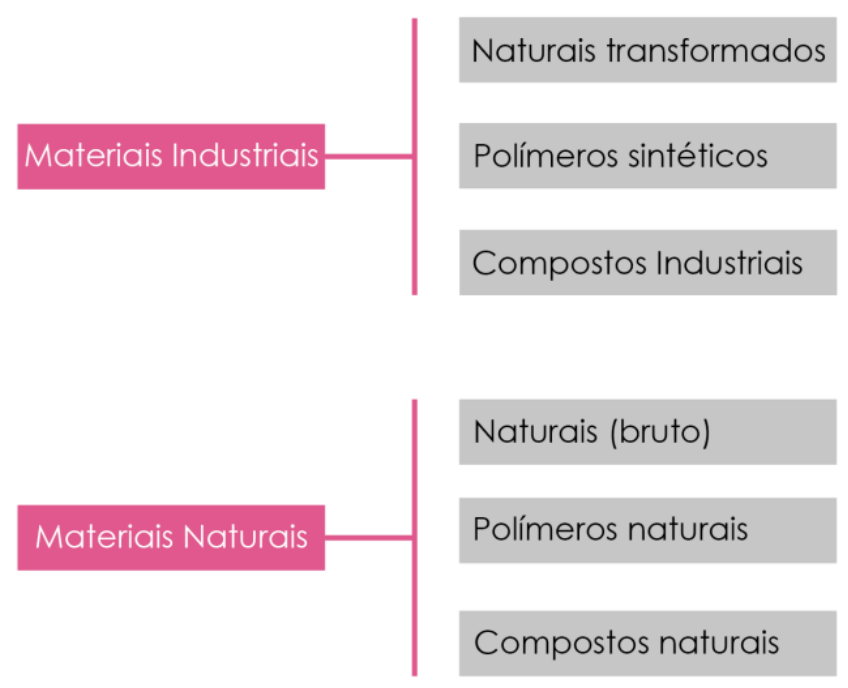

Fonte: Autores, 2021 com base em Guilgen e Kistmann, 2012.

Importante ressaltar que o caráter natural de um material não o qualifica necessariamente como sendo de origem sustentável. Por um lado, muitos podem advir do descarte irregular, e com a sua aplicação em produtos como a joia, possibilita uma destinação mais ecológica e rentável. Por outro lado, como é o caso das sementes, como aponta Benatti (2013, p:37) 'é fonte de alimento para a fauna, sendo necessário promover empresas que tenham certificação do produto garantindo a sua procedência, e desta forma, inibindo a exploração predatória'.

Um exemplo relevante é o do açaí, fruto muito consumido na região Norte do país, que vem conquistando outras regiões do Brasil e do mundo. Atualmente, o estado do Pará é o maior produtor com $86 \%$ da produção nacional e enfrenta problemas com os resíduos para a retirada da polpa, pois apenas $17 \%$ do fruto é utilizado na extração. As fibras e sementes restantes terminam por ser descartadas, em sua maioria, de forma irregular. (SATO, 2018).

Por mais que se trate de um material natural, com baixo processamento, como a produção nacional se concentra basicamente em um região, o descarte é maior do que o ambiente disponível consegue degradar. Assim, o uso de semente em produtos como a joia se mostra como alternativas para um material que está sem destinação, além da agregação de valor, pois após a sua aplicação em comparação ao valor inicial, pode ter um ganho financeiro de $840 \%$. (BENATTI, 2013).

A figura 2 apresenta dois exemplos de como esses materiais de origem industrial e natural podem ser empregados em acessórios sem que percam sua caracterização, pois o material, as técnicas de tratamento e acabamentos e as formas utilizadas influenciam na aceitação, ou não, de uma joia. Por mais que inovações surjam a cada dia, é importante ressaltar que a joalheria de mercado é um campo que explora e reinventa o tradicional, justamente pela sua valorização e pela usabilidade necessária. 
Figura 2: Par de brincos com material industrial e uma aliança e um anel com material natural.
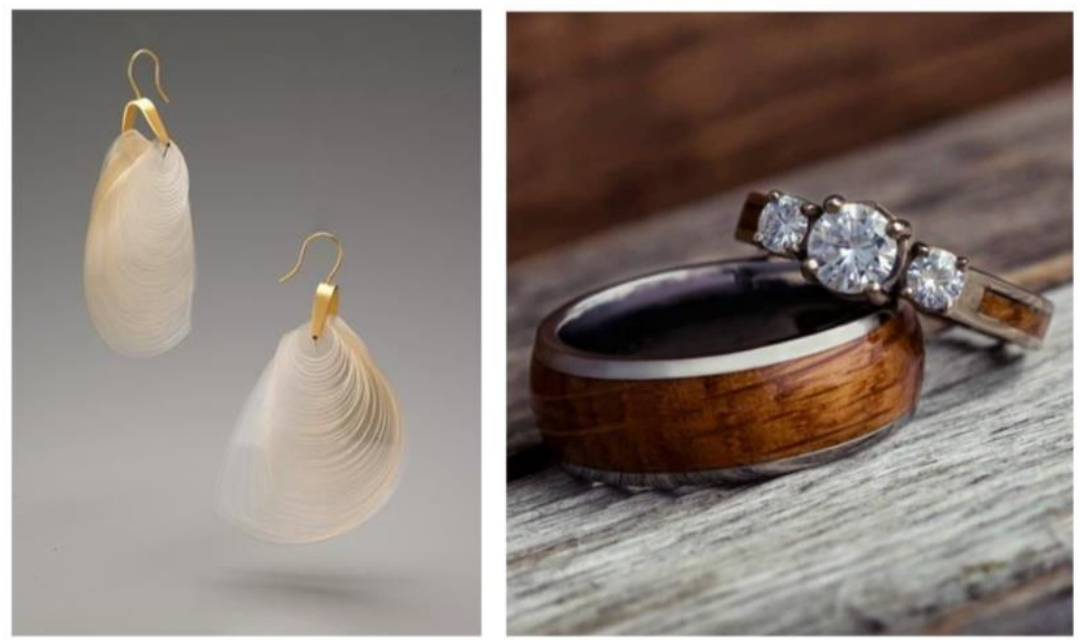

Fonte: <https://br.pinterest.com/pin/300474606360024886/>; <https://jewelrybyjohan.com/products/>.

No brinco criado pela designer Rita Baek (figura 2 à esquerda) é interessante notar que o ponto de destaque da peça é justamente a combinação do metal nobre com o polímero e o tratamento que o material recebeu. E mesmo as peças mais clássicas, como alianças e anéis de noivado (figura 2 à direita), estão adotando os materiais alternativos para destacá-las, como o trabalho realizado pela marca Norte americana Jewelry by Johan que combinou as gemas, ouro branco, titânio e madeira.

Por isso, mais do que criar uma peça cheia de conceitos, para Lee e Tomimatsu (2015) o designer contemporâneo tem de estar atento à atualidade e ao contexto externo, levando em consideração os aspectos sociológicos e antropológicos que se somariam a sua essência e ao conhecimento estético.

Dependendo da região do Brasil é possível notar o quanto o ambiente ao redor desse designer vai influenciá-lo nas suas escolhas de materiais e nas inspirações estéticas e formais das suas peças. Em diversos trabalhos desenvolvidos no estado do Pará, por exemplo, a narrativa amazônica da união de materiais naturais à estética da flora e fauna local se mostram presentes (figura 3). Para Cardoso (2013, p:68) 'na chamada 'era da informação', é praticamente impossível chegar a qualquer objeto sem passar antes pelo repertório'.

Figura 3: Joias contemporâneas paraenses.
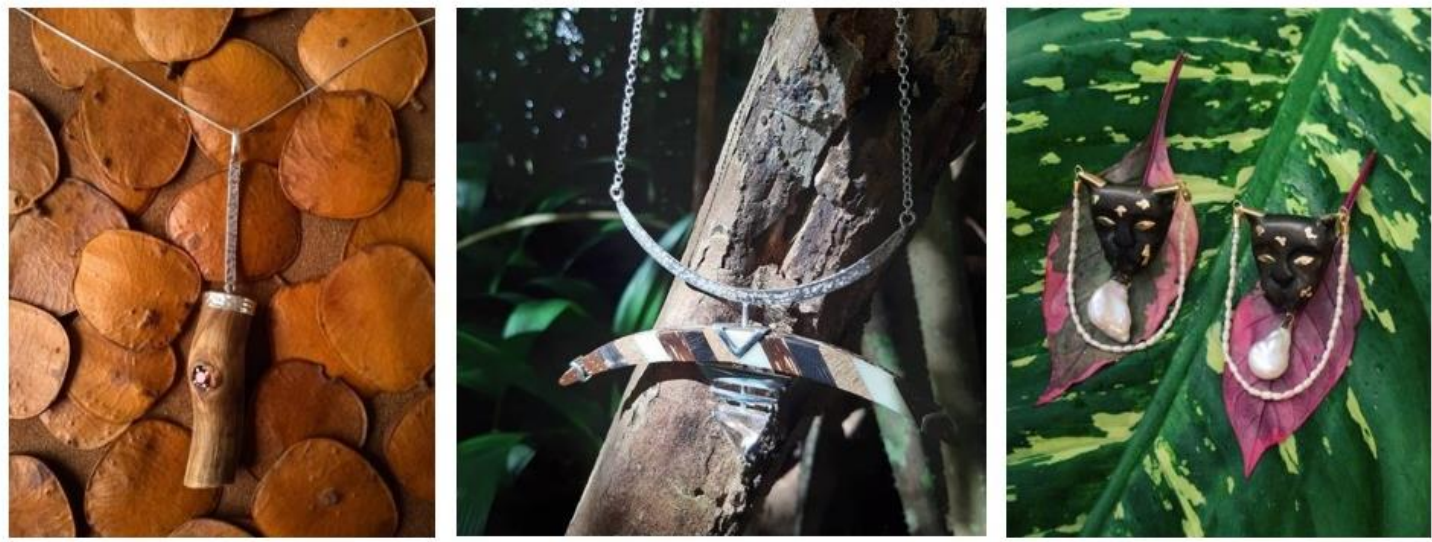

Fonte: Instagram.com - @brilhodamatajoias (esquerda); @yemaraatelie (centro); @barbaramuller_(direita).

As peças da figura 3 são de designers paraenses que utilizam materiais como madeira, 
chifre, osso, gemas, pérola de água doce além dos metais nobres prata e ouro. O primeiro colar (à esquerda) traz a madeira com aparência rústica ao mesmo tempo em que lida com a delicadeza visual do metal e da gema. Ao centro, há a combinação da técnica de marchetaria e a referência do arco e flecha com uma simbologia indígena, e os brincos (à direita) com a onça esculpida na madeira é combinada também a outros elementos. Essas são algumas características que vêm fortalecendo a imagem da joalheria paraense.

A produção joalheira do estado vem movimentando milhões no setor comercial, no Brasil os maiores consumidores são dos estados do Rio de Janeiro, São Paulo e Ceará e, internacionalmente, os principais mercados são os países da França, Estados Unidos, Bélgica, Portugal e Itália. (FURTADO, 2019).

São particularidades que vêm conquistando o mercado, é possível visualizar que '[...] o trabalho de alguns joalheiros contemporâneos é precisamente sobre o que significa para a joia existir em tais locais, e em que medida a consciência da relação entre objeto e sua localização é efetivamente seu tema.' (MERCALDI; MOURA, 2017, p:65).

Enquanto os materiais industriais são oriundos desses novos comportamentos de consumo, os naturais sempre estiveram presentes na vivência das suas regiões, mas que ultimamente vêm ganhando novos status e significados. Benatti (2013) reforça que a aceitação dos adornos com sementes está atrelada à consciência ambiental e a busca por produtos mais sustentáveis.

Os consumidores desses produtos normalmente exigem saber das suas procedências, como é produzido, quem fez, se causaram poluição, desmatamento ou mesmo, se é resultante do trabalho escravo, como apontou Rosa Helena, diretora executiva do Espaço São José Liberto - Polo Joalheiro do Pará. (FURTADO, 2019). A pesquisa de mestrado vinculada a esse trabalho tem como recorte espacial as joias contemporâneas produzidas no estado do Pará.

\subsection{Usabilidade e agradabilidade e suas percepções na joia}

Além dos aspectos estéticos, simbólicos e ecológicos que norteiam essa joalheria, é importante frisar as questões tecnológicas relacionadas à ergonomia do produto, pois esses aspectos também influenciam a percepção da qualidade do produto. A usabilidade das joias está associada aos aspectos mais funcionais do uso do produto: fechos, articulações e acabamentos dos materiais.

Segundo lida (2016), a usabilidade está ligada ao uso de produtos com segurança, eficiência, facilidade e comodidade não se restringindo apenas às características do produto, mas também de quem vai utilizá-lo, do que se pretende com ele, das tarefas e do ambiente onde será usado. Já a agradabilidade visa proporcionar prazer estético e simbólico ao consumidor. Envolve aspectos estéticos, como a combinação de formas, cores, materiais, texturas, acabamentos e movimentos, bem como aspectos simbólicos, com a identificação do produto com certas etnias, classes, grupos, valores sociais, status ou regiões.

A joia sempre esteve ligada à estética e às mensagens que seu portador transmite ao utilizá-la. A exemplo das grandes cerimônias como casamentos e formaturas que são marcadas por uma peça de joalheria, e a agradabilidade tem um papel fundamental nessa construção da joia, perante seu potencial usuário.

Segundo Jordan (2000) apud De Menezes (2007), a agradabilidade se relaciona com o prazer e o autor propõe uma estrutura metodológica que classifica em quatro os prazeres que um produto pode proporcionar ao usuário: fisiológico, social, psicológico e ideológico. Os três últimos são os mais recorrentes quando relacionados com o uso de joias, pois dizem respeito à imagem pessoal e o status que o produto ou serviço podem proporcionar, às reações emocionais e cognitivas das pessoas e aos valores e crenças relacionados à estética da peça.

'A agradabilidade não diz respeito simplesmente a uma propriedade de um produto, mas à interação do usuário com o produto. Essa interação deve ter como resultado algum tipo de prazer para o usuário, deve trazer benefícios emocionais e ser agradável.' (DE MENEZES, 2007, p:27). Nas joias está associada às questões percebidas pelo usuário em relação aos seus significados e aparência, se identificar com o produto e querer portá-lo.

Os autores desta pesquisa defendem que é importante selecionar os materiais com critérios de durabilidade e estética para que a joia não sofra depreciação, pois os materiais naturais 
possuem alta resistência à corrosão e oxidação, resistência mecânica, além da raridade, beleza e brilho característicos. (STRALIOTTO, 2008). Diante dessa reflexão, acredita-se ser necessário considerar os aspectos relacionados a usabilidade e a agradabilidade também em projetos de joias contemporâneas produzidas com sementes.

\subsection{0 uso de sementes na joalheria}

Entre os muitos materiais de origem natural que são utilizados na confecção de adornos, as sementes são materiais amplamente difundidos, encontradas em abundância em algumas regiões e com baixo custo, além do formato que facilita no processo de montagem. Mas, por se tratar de um material natural, dependendo do tratamento que recebe, pode vir a apresentar problemas que afetem seu tempo de vida.

Para que a semente esteja apta a ser utilizada em um acessório é necessário que ela passe por um processo de beneficiamento para a desvitalização e assim perca o seu poder de germinação, além de outros cuidados como a remoção da sua casca, polimento, tingimento, secagem e armazenamento. (BENATTI, 2013).

Se na joalheria tradicional a preocupação com a procedência da matéria-prima se refere aos cuidados ambientais dos processos de mineração e dos conflitos sociais gerados por esse processo, no uso de sementes a procedência do material impacta diretamente o resultado final da joia. Este ponto deve ser ressaltado pois sementes com secagem insuficiente, armazenagem inadequada e até mau uso pelo consumidor final podem acarretar na ação de fungos e insetos, ocasionando mudança de coloração, degradação rápida, surgimento de furos ou perda de partes da semente.

Apesar das qualidades percebidas ao se adotar esses materiais, a manutenção e durabilidade são aspectos que necessitam de atenção por parte dos designers, já que pode afetar a experiência do usuário com o produto. Como reforça Benatti (2013) é importante o cuidado na escolha dos processos e técnicas para que também não se altere o que de mais valor esse material tem a oferecer.

O consumidor que adquire uma joia que utiliza sementes como matéria-prima, por seu caráter sustentável, deve agir como um parceiro do produtor. É necessário entender que um material natural, minimamente processado, se degrada mais rápido e isso deve ser entendido como um ponto positivo, afinal esse é o principal aspecto que torna a joia com sementes um produto com perfil sustentável. Outro ponto é entender que, além do beneficiamento correto do material pelo produtor, o seu uso e manutenção pelo consumidor final também são importantes influências no tempo útil desse produto. Informar o consumidor e auxiliá-lo nessa manutenção fazem parte da produção de uma joia com sementes.

Nesse caso, os princípios de usabilidade e agradabilidade tendem a melhorar o produto ao proporcionar alterações nas características físicas da peça como dimensões, formas, resistência e materiais (IIDA, 2016). Mas a operacionalidade dela não deve ser considerada separadamente diante de uma preocupação prática, porém integrada ao projeto da joia como um todo (PORTO, 2018).

Todos esses pontos levantados possuem grande relevância no projeto da joia contemporânea, mas os aspectos de resistência e material têm grande importância na avaliação da aplicação da semente nas joias, visto que é um material que se diferencia, em termos de durabilidade, com outros mais nobres como os metais e, até mesmo, alguns de origem industrial como os polímeros. Benatti (2013) diz que a aplicação de sementes em produtos e a expectativa em relação a sua durabilidade variam. Mas, a partir do momento que ela é inserida no mercado das joias, esse tempo deve ser maior, pois a joia possui um valor monetário e de estima maior.

A Embrapa Amazônia Oriental (Empresa brasileira de pesquisa agropecuária) desenvolve o trabalho com sementes em parceria com a designer Rita Reis. $O$ trabalho já contabiliza peças que duram mais de dez anos sem que sofra com a ação do tempo. Um importante fator para isso é que a empresa prioriza a secagem das sementes em estufas e com luz ultravioleta, já nas produções artesanais a secagem é realizada ao sol (FURTADO, 2019). Mas os pequenos artesãos podem adotar, como alternativa, uma estufa caseira utilizando uma caixa de madeira e lâmpadas pois, no sol, as sementes não eliminam por completo a água do seu interior, e 
ficam suscetíveis à ação de micro-organismos. (BENATTI, 2013). Assim como o furo que elas recebem se torna uma porta de entrada para insetos, sendo necessário cuidados maiores no seu armazenamento de modo a criar uma barreira física contra eles. (NOGUEIRA, 2008).

As situações como as descritas acima reforçam que, o investimento em tecnologias e estudos no setor podem proporcionar um conhecimento maior a respeito desses insumos, seja para melhorar os saberes que, muitos produtores e comunidades já possuem em relação ao tratamento de materiais naturais, como para se desenvolver novas possibilidades. Além dos inúmeros benefícios, seja do ponto de vista da área acadêmica e/ou industrial, do comércio e da satisfação do usuário. Pois 'hoje, os consumidores esperam prazer, além de funcionalidade, de tudo que compram'. (ASHBY; JOHNSON, 2011, p:4).

\section{Método}

Esta revisão de literatura é um recorte da, pesquisa de mestrado, em andamento, do Programa de Pós Graduação em Design da Universidade Federal de Pernambuco (UFPE) que objetiva aumentar a percepção da qualidade da joalheria contemporânea sob os aspectos técnicos, estéticos e simbólicos a partir do tratamento da superfície de sementes naturais do Estado do Pará.

A pesquisa parte do pressuposto que há uma necessidade de se analisar como esses outros materiais se comportam em uma peça de joalheria; compreender a cadeia produtiva da matéria-prima desde a extração ao beneficiamento e estabelecer um viés ergonômico da aplicação de sementes e adoção de técnicas e tecnologias no tratamento da superfície destes materiais visando sua durabilidade.

Para tanto, foi proposto um mapa mental, a partir de Buzan (2009) como um instrumento para organizar as ideias iniciais da pesquisa, como forma de estimular reflexões para a seleção de novas referências. Inicialmente foi feita a determinação das Ideias de Ordenação Básicas (IOBs), para então utilizá-las como "ganchos" dando continuidade ao aprofundamento de itens a serem tratados no estudo (Figura 4).

No centro do mapa posiciona-se o objeto de estudo - joalheria contemporânea, destacada na cor laranja. As IOBs que radiam seu entorno são: território, materiais e qualidade do produto.

O eixo material se divide entre os tradicionais e os alternativos, dando destaque para os aspectos a serem tratados nas sementes. No eixo: qualidade do produto, os caminhos a serem tomados consideram os aspectos da usabilidade e da agradabilidade, já o território ramifica o estado do Pará e suas influências regionais no projeto da joia.

As ramificações dos eixos passam então a se conectarem em determinados momentos, indicando as ações que cada um exerce sobre o outro. O requisito "durabilidade" do eixo material possui alta relevância sobre os tópicos da usabilidade. Nesse processo, surgiu a necessidade de criação de um subitem ligando os eixos - território e materiais: os fornecedores, no qual a pesquisa deverá compreender a disponibilidade das sementes na região, bem como sua cadeia produtiva.

As ramificações contribuem para o entendimento dos temas que estão em volta do objeto de estudo, mas o mapa possui um recorte determinado pelos retângulos para enfatizar a linha de pesquisa pretendida dentro desse universo, e orienta assim quais os assuntos e termos a serem buscados na revisão de literatura que, a princípio, foi realizada principalmente por meios digitais em sites institucionais e em repositórios de teses de universidades que possuem linhas de pesquisa na área de joalheria, ergonomia e materiais naturais. 


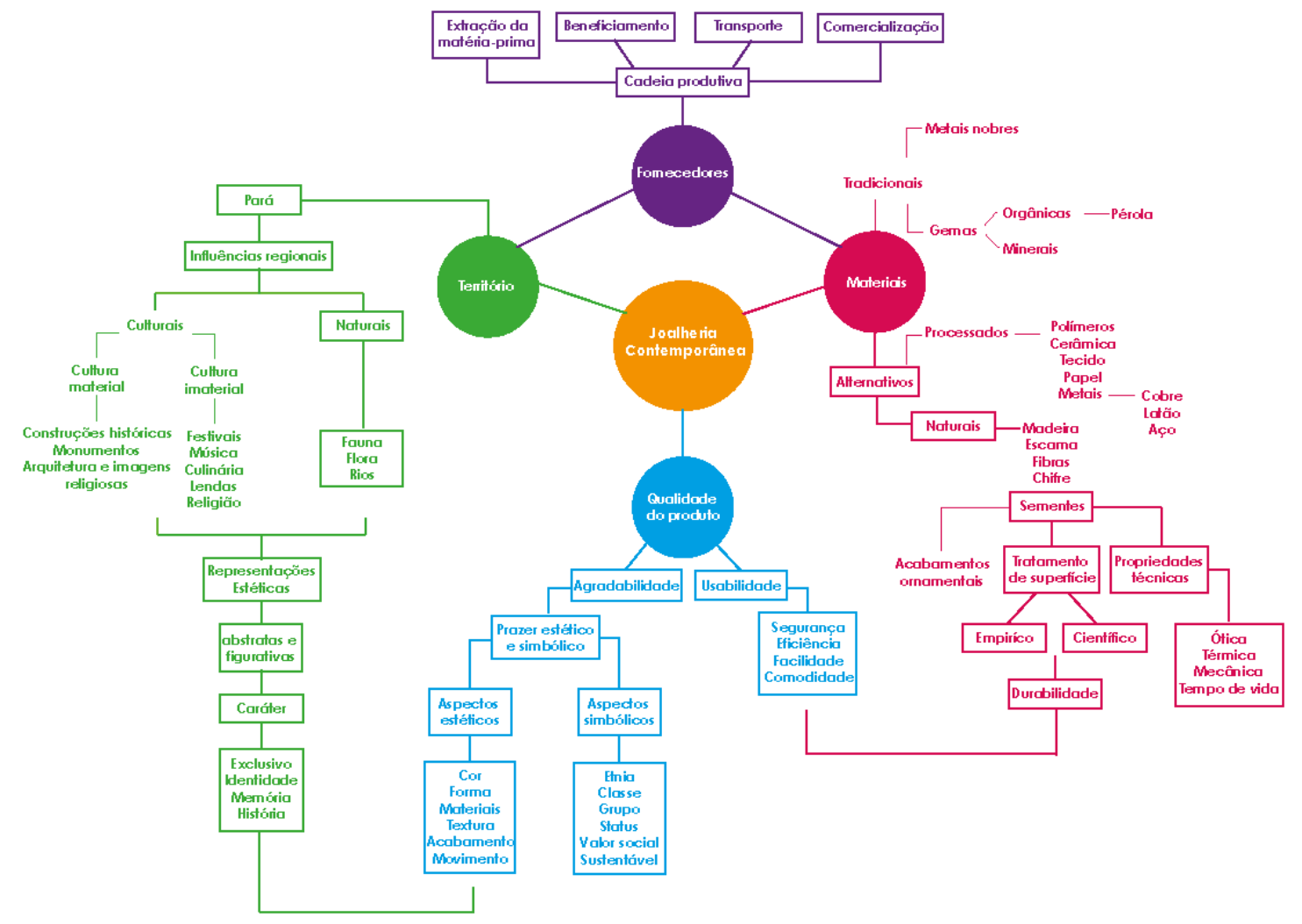

Fonte: Autores, 2021

Vale enfatizar que o Portal de periódicos da Capes foi um dos meios utilizados para o levantamento do estado da arte, com a combinação da revisão por pares, compreendidos no período entre os anos de 2015 a 2021 e utilizando as palavras-chave: natural seeds, seed, jewelry, usability, design e jewelry design, afim de encontrar publicações em outros países que pudessem estar trabalhando o uso de sementes na joalheria, mas nenhum dos resultados forneceram materiais relevantes para a pesquisa.

Na sequência, utilizamos os repositórios de teses para pesquisa utilizando a combinação das palavras chaves: joalheria contemporânea; joias; ergonomia; usabilidade; agradabilidade; sementes; materiais e design. A seleção das publicações foi feita a partir da análise do resumo, dos tópicos do texto e/ou do sumário, quando presente, como critério de seleção (figura 5).

Dos cinco eixos estabelecidos no mapa, apenas as referências de joalheria contemporânea, materiais e qualidade do produto foram utilizadas para a discussão, apesar dos eixos território e fornecedores terem suas temáticas exploradas ao longo do artigo. Os aspectos dos fornecedores, mais precisamente, não foram priorizados, pois o enfoque pretendido está na visualização da usabilidade e da agradabilidade dos materiais alternativos na joia, porém vale destacar a importância da sua abordagem mais à frente para levantar informações sobre as formas de exploração e obtenção das sementes. 
Figura 5: Seleção de dissertações, teses e artigos relevantes a revisão de literatura da pesquisa.

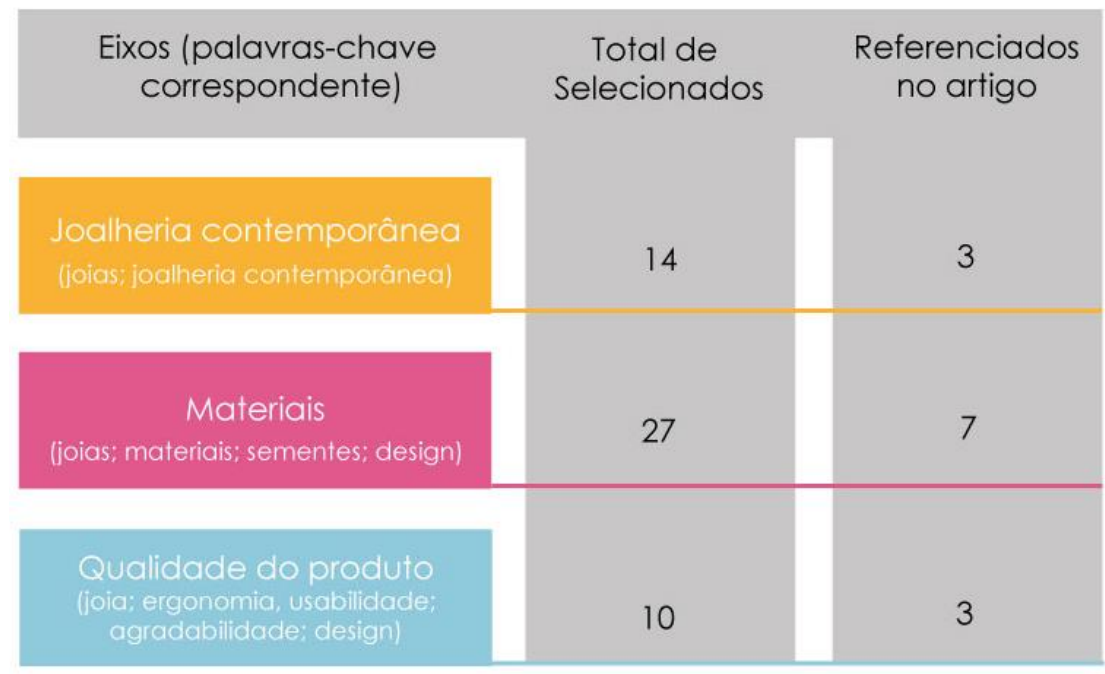

Fonte: Autores, 2021.

Como resultado desse processo um total de cinquenta e uma (51) publicações foram encontradas, dentre os três eixos, todavia trinta (30) foram classificadas como relevantes e treze (13) delas tiveram destaque pela abordagem em relação aos temas pretendidos.

Quadro 1: Seleção das publicações com relevância ao tema da pesquisa.

\begin{tabular}{|c|c|c|c|}
\hline EIXO & TÍTULO & FONTE & ANO \\
\hline \multirow{3}{*}{$\begin{array}{l}\text { Joalheria } \\
\text { contemporânea }\end{array}$} & Definições da joia contemporânea & $\begin{array}{l}\text { Moda palavra E- } \\
\text { periódico }\end{array}$ & 2017 \\
\hline & $\begin{array}{l}\text { Materiais e processos não-tradicionais utilizados } \\
\text { no design de joias contemporâneo }\end{array}$ & Colóquio de moda & 2012 \\
\hline & Estéticas do design de joias contemporâneas & $\begin{array}{l}\text { Revista Espaço } \\
\text { acadêmico }\end{array}$ & 2015 \\
\hline \multirow{7}{*}{ Materiais } & $\begin{array}{l}\text { Inovação nas técnicas de acabamento } \\
\text { decorativo em sementes ornamentais } \\
\text { brasileiras: design aplicado a produtos com } \\
\text { perfil sustentável }\end{array}$ & $\begin{array}{l}\text { Universidade do } \\
\text { Estado de Minas } \\
\text { Gerais }\end{array}$ & 2013 \\
\hline & Ecodesign aplicado ao design de jóias & Colóquio de moda & 2008 \\
\hline & $\begin{array}{l}\text { Dossiê técnico - Tratamento preventivo e } \\
\text { curativo de sementes para confecção de } \\
\text { artesanato }\end{array}$ & $\begin{array}{l}\text { Universidade de } \\
\text { Brasília }\end{array}$ & 2007 \\
\hline & $\begin{array}{l}\text { Joias elaboradas a partir de resíduos de } \\
\text { madeira }\end{array}$ & Disciplinarum Scientia & 2019 \\
\hline & $\begin{array}{l}\text { Insetos broqueadores de sementes e } \\
\text { aproveitamento de sementes para confecção de } \\
\text { biojóias e artesanato }\end{array}$ & $\begin{array}{l}\text { Universidade Federal } \\
\text { Rural do Rio de } \\
\text { Janeiro }\end{array}$ & 2008 \\
\hline & $\begin{array}{l}\text { Desafios para a Circularidade na Joalheria } \\
\text { Autoral Fluminense }\end{array}$ & $\begin{array}{l}\text { 5 Simpósio de Pós- } \\
\text { graduação em Design } \\
\text { da ESDI }\end{array}$ & 2019 \\
\hline & $\begin{array}{l}\text { Biocarvão de resíduos de açaí como } \\
\text { condicionante de solos }\end{array}$ & $\begin{array}{l}\text { Universidade Federal } \\
\text { Rural da Amazônia }\end{array}$ & 2018 \\
\hline $\begin{array}{l}\text { Qualidade do } \\
\text { produto }\end{array}$ & $\begin{array}{l}\text { Análise da ergonomia e usabilidade dos } \\
\text { sistemas de fechos utilizados na indústria } \\
\text { joalheira }\end{array}$ & $\begin{array}{l}\text { Universidade do } \\
\text { Estado de Santa } \\
\text { Catarina }\end{array}$ & 2018 \\
\hline
\end{tabular}




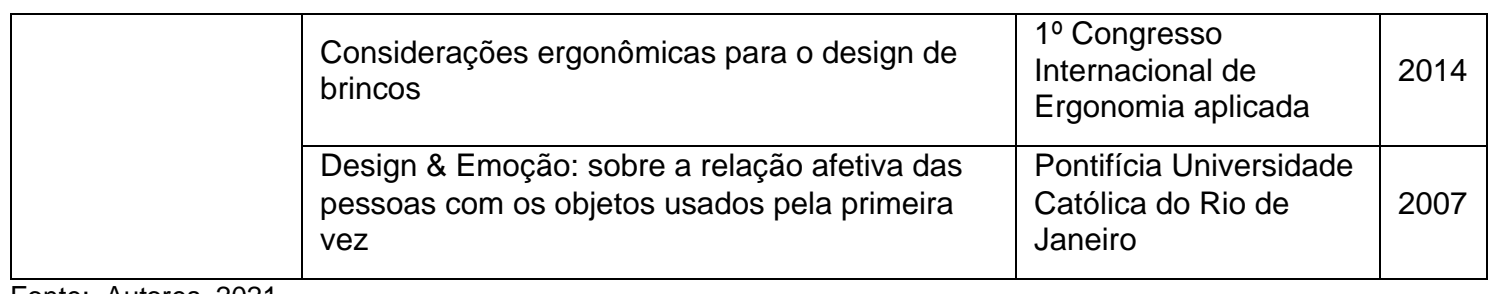

Fonte: Autores, 2021.

O Quadro 1 apresenta o elenco das publicações analisadas e consideradas estado da arte deste tema de pesquisa. Três (03) no eixo da joalheria contemporânea; sete (07) no eixo de materiais que discutiam o uso de materiais alternativos nas joias ou do tratamento de sementes e, três (03) no eixo na qualidade do produto que abordavam a ergonomia e a usabilidade em joias.

\section{Resultados}

\subsection{Usabilidade e agradabilidade no uso de sementes em joias contemporâneas}

O projeto da joia não costuma levantar as questões de ergonomia típicas de um posto de trabalho e nem de usabilidade como em produtos utilitários, são questões que estão mais intrínsecas ao longo do processo de elaboração das peças, mas como expõe Rabenschlag et al (2019, p:5):

$\mathrm{Na}$ joia, a ergonomia se apresenta especialmente no conforto e na qualidade das peças, pois ela entra em contato direto com o corpo do usuário e não deve causar danos à saúde. Por esse motivo, os aspectos avaliados correspondem a peso, dimensões, forma, modo como as peças são montadas e produzidas e processos de acabamento.

O contato direto da joia com o corpo faz com que um dos principais pontos a serem considerados sejam os materiais que serão empregados, o peso da peça, a sua superfície, o cheiro, a coloração e o seu comportamento com o passar do tempo são aspectos diretamente relacionados ao material. E na joalheria contemporânea, com a adoção de diferentes materiais, há a necessidade de se pensar como essas combinações poderão ocorrer sem impactar de forma negativa a percepção do usuário em relação à joia.

É possível pontuar a partir dos conceitos da usabilidade, proposto por lida (2016), e da agradabilidade, pontuado por Jordan (2000), aspectos que devem ser observados para a joia produzida com sementes. Para a usabilidade, o esperado do produto é que se considere os requisitos: segurança, comodidade, facilidade e eficiência.

A segurança em uma joia pode estar atrelada a fatores estruturais como elos, fechos e cravações das gemas. É necessário cuidado com extremidades e junções para que não haja risco de lesões na pele, ou mesmo de engates em peças de roupas, cabelos ou qualquer outro objeto que o usuário possa entrar em contato. Também, há riscos voltados aos materiais, como reações alérgicas a metais ou mesmo ao material alternativo empregado. No caso das sementes, é importante o cuidado com os produtos utilizados para o seu tratamento. Matos e Rodrigues (2007) ressaltam que alguns artesãos se utilizam de substâncias tóxicas para combater eventuais parasitas, o que pode resultar em danos à saúde do usuário que entrar em contato com a peça. Entre as lesões que podem ser provocadas pelo peso da joia, o exemplo mais recorrente está no rompimento do lóbulo da orelha pelo uso de brincos pesados. (BATISTA, 2014).

A comodidade tem uma relação direta com a segurança, sobre o material empregado diz respeito às questões de manutenção e limpeza que as joias podem, com o tempo, vir a demandar, tanto os metais em decorrência da sua oxidação, como a semente por ser um material natural e sujeita a ação de microorganismos. Se não for possível realizar a troca da semente, o que já seria incômodo, tendo em vista que o consumidor teria que se deslocar ou enviar a peça, a joia vai se descaracterizar e perder o valor percebido conquistado na adoção das sementes. A comodidade também está presente nas configurações de tamanho e peso do produto e podem impactar na experiência do usuário. 
A depender da região do país, as sementes têm grande disponibilidade no mercado. Por isso, no terceiro requisito que é a facilidade, elas possuem vários aspectos positivos como a fácil usinagem, que são os tratamentos de furo, serra, lixa, entre outros (BENATTI, 2013), a montagem que se dá geralmente através dos furos, além de possuir valor monetário acessível.

Por último, a eficiência vem tratar do que é esperado de um produto e a facilidade que $o$ portador da peça terá em atingir os seus objetivos ao usá-lo. Aqui é possível fazer a ligação com os próximos requisitos referentes à agradabilidade, pois o esperado de uma joia é que ela consiga transmitir ao seu portador e a quem o observa valores e preferências, assim como seus aspectos funcionais possam permitir que a joia seja utilizada, sem problemas no seu manuseio. Uma síntese dos aspectos referentes à usabilidade discutidos neste trabalho estão apresentados no Quadro 2.

Quadro 2: Aspectos de usabilidade que devem ser considerados no projeto de joias contemporâneas.

\begin{tabular}{|l|l|}
\hline \multicolumn{2}{|l|}{ A Usabilidade nas joias com sementes } \\
\hline SEGURANÇA & $\begin{array}{l}\text { Partes que não se soltam; Não causa lesões na pele; Não se agarra a } \\
\text { pelos/cabelos corporais; Não danifica roupa; Não reage com a pele/suor; } \\
\text { Não causa alergias; Resistente a choques leves, condizentes com o uso; } \\
\text { Está livre de fungos/insetos }\end{array}$ \\
\hline COMODIDADE & $\begin{array}{l}\text { Facilidade de limpeza; Armazenamento simples; Facilidade de acesso a } \\
\text { informação sobre sua manutenção; Facilidade de manutenção; Peso da } \\
\text { peça condizente com o seu uso; Conforto ao toque }\end{array}$ \\
\hline FACILIDADE & $\begin{array}{l}\text { Acesso à matéria-prima; Custo acessível; Facilidade de usinagem e } \\
\text { tingimento; Identificação de origem }\end{array}$ \\
\hline EFICIÊNCIA & $\begin{array}{l}\text { Ao seguir os quesitos de segurança, comodidade e facilidade, ainda } \\
\text { consegue transmitir valores e estilo ao consumidor. }\end{array}$ \\
\hline Fonte: Autores, 2021. &
\end{tabular}

Para as percepções relacionadas a agradabilidade, há dois aspectos norteadores: os estéticos e os simbólicos. Esses dois pontos se interconectam pois suas características são dependentes umas das outras. Não é possível estabelecer simbolismos a um produto sem a aparência estética, da mesma forma que a mensagem por trás da peça é em decorrência do que está sendo visualizado.

Os aspectos estéticos evidenciados são referentes a várias características como as formas empregadas, que no caso das sementes é limitado. Se por um lado a sua forma pode facilitar o processo de montagem, por outro não possibilita muitas variações e acabamentos, apesar da possibilidade do emprego de cores, através de tingimentos, e tamanhos distintos. A textura da semente, seja ela uma característica intrínseca ou provocada, e todos esses outros pontos citados podem ser explorados como um elemento diferencial.

Por trás dos aspectos simbólicos há vários caminhos que podem ser considerados e alguns importantes para o conhecimento do público alvo. Para Cardoso (2013, p:62) 'Sem um sujeito capaz de atribuir significado, o objeto não quer dizer nada; ele apenas é'. Por isso é importante considerar as questões de cunho social como etnia, classe e faixa etária, além do ambiente que se está inserido, no processo de fazer design. Ao portar uma joia o usuário pode estar em busca de status, objetiva valorizar a produção local ou simplesmente foi cativado pelas suas formas e cores. O quadro 3 apresenta uma síntese para análise da agradabilidade de um produto. 
Quadro 3: Aspectos de agradabilidade que devem ser considerados no projeto de joias contemporâneas.

\begin{tabular}{|c|c|c|c|}
\hline \multicolumn{4}{|c|}{ A Agradabilidade nas joias com sementes } \\
\hline \multicolumn{2}{|c|}{ ASPECTOS ESTÉTICOS } & \multicolumn{2}{|c|}{ ASPECTOS SIMBÓLICOS } \\
\hline $\begin{array}{l}\text { Elementos de } \\
\text { composição }\end{array}$ & $\begin{array}{l}\text { Linha, forma, volume, } \\
\text { textura, cor, dimensão, } \\
\text { material, cheiro, som }\end{array}$ & $\begin{array}{l}\text { Característica: } \\
\text { aspectos qualitativos } \\
\text { da aparência }\end{array}$ & $\begin{array}{l}\text { Exemplos: rústico, } \\
\text { discreto, despojado, } \\
\text { colorido, sóbrio, } \\
\text { elegante, místico, } \\
\text { charmoso }\end{array}$ \\
\hline Princípios do design & $\begin{array}{l}\text { Escala, proporção, } \\
\text { equilíbrio, ritmo, } \\
\text { ênfase, } \\
\text { unidade/variedade }\end{array}$ & $\begin{array}{l}\text { Caráter: aspectos } \\
\text { sensoriais }\end{array}$ & $\begin{array}{l}\text { Exemplos: respeito, } \\
\text { diversão, alegria, } \\
\text { saudade, otimismo, } \\
\text { confiança, força }\end{array}$ \\
\hline
\end{tabular}

Fonte: Autores, 2021, com base na ferramenta QDP - Design de Moreira, 2010.

A maioria desses aspectos estão ao alcance do designer e ele, por sua vez, precisa utilizar das suas habilidades projetuais para conquistar seu potencial consumidor. Norman (2002) enfatiza que o design é um ato de comunicar e, por isso, a importância de se conhecer as pessoas com quem vão dialogar. Para Jordan (2000) 'para se atingir o público consumidor, é necessário atender a três requisitos: entender os consumidores; saber o que querem e dar a eles o que querem' (DE MENEZES, 2007, p:62).

\section{Considerações}

A joalheria contemporânea já faz parte desse novo mercado consumidor, então é importante questionar sobre todos os aspectos envolvidos na sua criação. É entender o que representa na sociedade atual, quais setores movimenta, seus impactos na região ao qual pertence e as possibilidades de inovação que pode gerar. Apesar de ainda não haver um consenso em relação ao seu conceito, ela é caracterizada pela aplicação de materiais diferenciados e com formas e significados que comunicam muito mais que o valor monetário percebido.

As sementes apresentam algumas limitações quanto a variedade da sua forma, mas em contrapartida ser um material natural lhe confere aspectos que os metais não conseguem alcançar, como as texturas que cada uma carrega. A dificuldade de padronização entre elas torna cada peça única. Da mesma forma que carregam aspectos sensoriais de uma localidade, dão vida à memória dos povos nativos e transbordam fronteiras até o cenário urbano onde seus consumidores se encontram.

Mas para que essa joia conquiste seu consumidor é necessário novas abordagens para além da sua estética e simbolismos, considerando as limitações do material quanto aos quesitos de usabilidade e durabilidade. Para isso, trabalhar o tratamento de superfície se mostra como uma alternativa de melhoria na qualidade do produto, a bibliografia demonstra que existe essa preocupação por parte de quem trabalha com a semente, mas que podem ser melhor desenvolvidas e compartilhadas junto a outros profissionais.

O cenário demonstra a necessidade de se aprofundar no assunto. O mercado da joalheria contemporânea vem se expandindo assim como a exigência por produtos de qualidade, inovadores e bem resolvidos social e ecologicamente. É um ideal que, por mais difícil que seja de chegar, deve ser provocado e buscado.

\section{Referências}

Ashby, Michael; Johnson, Kara. (2011). Materiais e design: arte e ciência da seleção de materiais no design de produto. Rio de Janeiro: Elsevier.

Batista, Claudia Regina (2014). Considerações ergonômicas para o design de brincos. In: 1o CONAERG - Congresso Internacional de Ergonomia aplicada. 
Benatti, Lia Paletta. (2013). Inovação nas técnicas de acabamento decorativo em sementes ornamentais brasileiras: Design aplicado a produtos com perfil sustentável. Dissertação de mestrado. Programa de Pós-graduação em Design. Universidade do Estado de Minas Gerais. Disponível em: <http://mestrados.uemg.br/ppgd-producao/dissertacoes$\mathrm{ppgd/file/267-inovacao-nas-tecnicas-de-acabamento-decorativo-em-sementes-ornamentais-}$ brasileiras-design-aplicado-a-produtos-com-perfil-sustentavel>. Acesso em: 27 mar 2021.

Buzan, Tony (2009). Mapas mentais. Rio de Janeiro: Sextante.

Cardoso, Rafael. (2013). Design para um mundo complexo. São Paulo: Cosac Naify.

De Menezes, Cristiane Schifelbein (2007). Design e Emoção: Sobre a relação afetiva das pessoas com os objetos usados pela primeira vez. Dissertação de mestrado. Programa de Pósgraduação em Design do Departamento de Artes e Design. Pontifícia Universidade Católica do Rio de Janeiro. Disponível em: <https://www.maxwell.vrac.pucrio.br/colecao.php?strSecao=resultado\&nrSeq=10319@1 >. Acesso em: 27 mar 2021.

Furtado, Victor. (2019). Indústria sustentável: Sementes e cascas ganham status de joias da Amazônia. O liberal, Belém, 17 Nov. 2019. Folha cidades e atualidades, p. 8 e 9. Disponível em: Disponível em: <https://www.oliberal.com/cascas-e-sementes-ganham-status-de-joiasna-amazonia-1.213193>. Acesso em: 27 mar 2021.

Guilgen, Carolina de Araujo; Kistman, Virginia Borges. (2012). Materiais e processos nãotradicionais utilizados no design de joias contemporâneo. Colóquio de Moda. Disponível em: <http://www.coloquiomoda.com.br/anais/Coloquio\%20de\%20Moda\%20\%202013/COMUNICACAO-ORAL/EIXO-6-PROCESSOS-PRODUTIVOS_COMUNICACAOORAL/Materiais-e-processos-nao-tradicionais-utilizados-no-design-de-joiascontemporaneo.pdf>. Acesso em: 15 mar 2021.

lida, Itiro. (2016). Ergonomia: projeto e produção / Itiro lida, Lia Buarque de Macedo Guimarães. - 3. Ed. - São Paulo: Blucher.

Jordan (2000) apud De Menezes, Cristiane Schifelbein (2007). Design e emoção: Sobre a relação afetiva das pessoas com os objetos usados pela primeira vez. Dissertação de mestrado. Programa de Pós-graduação em Design do Departamento de Artes e Design. Pontifícia Universidade Católica do Rio de Janeiro. Disponível em: <https://www.maxwell.vrac.pucrio.br/colecao.php?strSecao=resultado\&nrSeq=10319@1>. Acesso em: 27 mar 2021.

Lee, Erika Yamamoto; Tomimatsu, Maria Fusako. (2015). Estéticas do design de joias contemporâneas. Revista espaço acadêmico, no 170, pp. 24-42. Disponível em: $<$ https://periodicos.uem.br/ojs/index.php/EspacoAcademico/article/view/27050>. Acesso em: 27 mar 2021.

Leonel, Felipe (2019). Contaminação por mercúrio se alastra na população Yanonami. Rio de Janeiro: Escola Nacional de Saúde Pública Sergio Arouca INFORME ENSP. Disponível em: <Contaminação por mercúrio se alastra na população Yanomami (fiocruz.br)>. Acesso em: mar 2021.

Manzini, Ezio; Vezzoli, Carlo. (2016). O desenvolvimento de produtos sustentáveis: os requisitos ambientais dos produtos industriais. São Paulo: Editora da Universidade de São Paulo.

Matos, Eduardo Henrique da S. F.; Rodrigues, Marcelo Nascimento (2007). Dossiê Técnico: Tratamento Preventivo e Curativo de Sementes para Confecção de Artesanato. Centro de Apoio ao Desenvolvimento Tecnológico. Universidade de Brasília

Moreira, Samantha C. O. (2010). QDP-Design: metodologia para gerar soluções assertivas a partir de conceitos criativos. Anais do 9o Congresso Brasileiro de Pesquisa e Desenvolvimento em Design, São Paulo.

Milam, Bruna. (2019). Desafios para a Circularidade na Joalheria Autoral Fluminense. 5ํㅗㅇósio de Pós-Graduação em Design da ESDI, Rio de Janeiro. Disponível: $<$ https://www.even3.com.br/anais/spgd_2019/225890-desafios-para-a-circularidade-najoalheria-autoral-fluminense/> Acesso em: 15 mar 2021.

Mercaldi, Marlon Aparecido; Moura, Mônica. (2017). Definições da joia contemporânea. Moda palavra E-períodico, Santa Catarina, n. 19, pp. 54-67. 
Nogueira, Ellen Aparecida (2008). Insetos broqueadores de sementes e aproveitamento de sementes para confecção de biojóias e artesanato. Monografia. Instituto de Florestas. Universidade Federal Rural do Rio de Janeiro.

Norman, Donald A. (2006). O design do dia-a-dia. Rio de Janeiro: Rocco.

Porto, Alexandra Marcela de Souza (2018). Análise da ergonomia e usabilidade dos sistemas de fechos utilizados na indústria joalheira. Dissertação de mestrado. Programa de Pósgraduação em Design do Centro de Artes. Universidade do Estado de Santa Catarina. Disponível em:

<https://www.udesc.br/arquivos/ceart/id_cpmenu/1229/ALEXANDRA_MARCELA_DE_SOUZ A_PORTO_Disserta_o_15513672519361_1229.pdf>. Acesso em: 27 mar 2021.

Rabenschlang, Rosane Abaz; Pelizan, Miguel Antônio; Pupim, Viviane Marcelo; Tabarelli, Taiane R. Elesbão. (2019). Joias elaboradas a partir de resíduos de madeira. Disciplinarum Scientia. Santa Maria, v. 20, n. 1, pp. 1-21. Disponível em:

<https://periodicos.ufn.edu.br/index.php/disciplinarumNT/article/view/2999>. Acesso em: 27 mar 2021.

Sato, Michel Keisuke. (2018). Biocarvão de resíduos de açaí como condicionante de solos. Tese (Doutorado em Agronomia) - Universidade Federal Rural da Amazônia, Belém. Disponível em: <http://repositorio.ufra.edu.br:8080/jspui/handle/123456789/468>. Acesso em: 15 mar 2021.

Straliotto, Luiz M. (2008). Ecodesign aplicado ao design de jóias. Colóquio de moda. Disponível em: <http://www.coloquiomoda.com.br/anais/Coloquio\%20de\%20Moda\%20\%202008/42377.pd>. Acesso em: 29 mar 2021. 